Article

\title{
Citric Acid Injections: An Accessible and Efficient Method for Controlling Outbreaks of the Crown-of-Thorns Starfish Acanthaster cf. solaris
}

\author{
Alexander C. E. Buck ${ }^{1, *}$, Naomi M. Gardiner ${ }^{1}$ and Lisa Boström-Einarsson ${ }^{1,2}$ \\ 1 Marine Biology and Aquaculture, College of Science and Engineering, James Cook University, Townsville, \\ QLD 4811, Australia; naomi.gardiner@jcu.edu.au (N.M.G.); lisa.bostromeinarsson@my.jcu.edu.au (L.B.-E.) \\ 2 Australian Research Council Centre of Excellence for Coral Reef Studies, James Cook University, Townsville, \\ QLD 4811, Australia \\ * Correspondence: alexander.buck@my.jcu.edu.au; Tel.: +61-04-2313-7575
}

Academic Editors: Sven Uthicke and Michael Wink

Received: 10 October 2016; Accepted: 3 December 2016; Published: 10 December 2016

\begin{abstract}
Outbreaks of the crown-of-thorns starfish (Acanthaster cf. solaris, COTS) are one of the primary causes of coral decline in the Indo-Pacific region. Effective methods to control COTS outbreaks may therefore be one of the most direct and immediate ways to reduce coral loss. However, the cost and logistical challenges associated with current control methods have undermined the effectiveness of many control efforts. In this study, we tested the feasibility of using powdered citric acid, which is widely available and low-cost, as an injection chemical for COTS control. We tested what combination of concentration, number of injections, volume, and water type were most efficient at killing COTS. All COTS injected in two or four sites died, irrespectively of the concentration of citric acid used, while single injections failed at reaching $100 \%$ mortality. The fastest combination was the injection of $150 \mathrm{~g} \cdot \mathrm{L}^{-1}$ citric acid solution in four injection sites $(5 \mathrm{~mL}$ per site), which killed the starfish in $26.4 \pm 4 \mathrm{~h}$. These results suggest that injections of powdered citric acid are an effective, economical, and widely available alternative to current COTS control methods.
\end{abstract}

Keywords: COTS; outbreak; control methods; pest control; coral reefs; injections

\section{Introduction}

Periodic outbreaks of Acanthaster cf. solaris (crown-of-thorns starfish, COTS) represent one of the single biggest threats to tropical coral reefs in the Indo-Pacific [1,2]. The corallivorous starfish can cause extensive damage when present at outbreak densities on coral reefs. For example, a large outbreak in Guam reduced live coral cover by more than $90 \%$ over a period of 2-3 years [3]. On Australia's Great Barrier Reef (GBR), mean live coral cover has halved between 1985 and 2012, and $40 \%$ of that coral loss is attributed to COTS [4,5]. Preventing and managing COTS outbreaks is therefore a major priority for environmental science and resource management, and may be the most immediate and effective mechanism to prevent ongoing coral loss across the Indo-Pacific [6]. Management of most anthropogenic disturbances that threaten coral reefs (e.g., climate-induced disturbances and declining water quality) require large-scale interventions and international policy changes [7]). In contrast, management of localised outbreaks of COTS are potentially feasible and may significantly increase the resilience of coral reef communities [5]. However, finding efficient, cheap, and safe methods that can be applied at large scales and across developed and developing nations has proven challenging [8].

Historically, a wide range of methods have been employed to cull COTS [8], however, most have been inefficient or damaging to the marine environment. Currently, large-scale control programs for COTS involve a single injection of a bile salt solution, which effectively kills COTS in less than $24 \mathrm{~h}[9,10]$. However, bile salts can be expensive, are only accessible through specialised suppliers, and 
carry quarantine restrictions that impede international operations [11]. Thus, for many communities in remote areas of the Indo-Pacific that experience recurrent COTS outbreaks, it can be difficult to obtain bile salts. To overcome these challenges, recent research has been investigating the potential use of alternate chemicals that are cheap, readily available, easy to deploy, safe to both the marine environment and to humans, and equally efficient at killing COTS as bile salts. To date, injections with cooking salt solution, vinegar, and lime juice have been demonstrated to be both lethal to COTS and safe for the environment [12-17]. However, not all of these chemicals are viable for large-scale control programs in remote coral reef regions. For instance, the high quantities of cooking salt and limes required during extensive control programmes may be challenging to transport in remote locations [16]. Limes are not readily available in all seasons nor in all locations, which may increase their price. In addition, juice extraction is labour-intensive, adding labour costs to control programmes, and the juice may deteriorate if not rapidly used [15]. Instead, this study examines the viability of using powdered citric acid, which can be purchased locally from grocery stores, is inexpensive, readily available, and has a long shelf life.

For a large-scale COTS control programme to be efficient, it is critical that any method employed achieves $100 \%$ COTS mortality. Achieving complete mortality depends not only on the efficiency of the injected chemical, but also on the technique used when administering the injection. Recent studies have revealed the importance of the number of injections [12,15], the size of the needle [10,12], location of injection site [10], and the volume or concentration injected $[12,13,15,18]$. For example, a single injection of $20 \mathrm{~mL}$ of lime juice did not kill $100 \%$ of treated COTS, while splitting the volume between two injection sites did [15]. Furthermore, a single $20 \mathrm{~mL}$ injection of vinegar with a 16-gauge $(1.2 \mathrm{~mm}$ inner diameter) needle resulted in $100 \%$ mortality, but using a $4 \mathrm{~mm}$ diameter needle reduced mortality to $87 \%$ [12]. The ideal injection method hinges on finding the optimal combination of techniques, using chemicals readily available in the local area.

The aim of this study was, therefore, to investigate the potential of using powdered citric acid as an efficient and cost-effective method to cull COTS. To achieve this, we aimed to determine: (1) the lowest effective concentration and number of injection sites needed to obtain $100 \%$ mortality, (2) the most effective injection volume, and (3) the efficiency of untreated seawater compared to distilled water as solvent for the citric acid solution. Finally, we compared the efficiency of citric acid injections to other chemical products in order to provide management recommendations.

\section{Materials and Methods}

\subsection{Collection Site and Maintenance Conditions}

The study was carried out at Lizard Island $\left(14^{\circ} 40^{\prime} \mathrm{S}, 145^{\circ} 28^{\prime} \mathrm{E}\right)$, Northern GBR, Queensland, Australia in February 2015. Adult $A$. cf. solaris were collected from reefs around Lizard Island and transported to Lizard Island Research Station in plastic aquaria $(64 \times 41 \times 40 \mathrm{~cm}$, max. 20 COTS per aquaria) with aerators. Then, COTS were allowed to acclimatise for at least $24 \mathrm{~h}$ in two large aerated holding tanks ( $160 \mathrm{~cm}$ diameter $\times 50 \mathrm{~cm}$ deep) with flow-through ambient seawater. Injured and weak specimens were discarded. Specimens were then measured from the tip of one randomly selected arm to the tip of the diametrically opposite arm (mean size $28.2 \pm 0.4 \mathrm{~cm} \mathrm{SE}$ ) and placed individually in aquaria $(40 \times 30 \times 25 \mathrm{~cm})$ with flow-through ambient seawater.

This study was conducted in accordance with James Cook University ethical guidelines and the Queensland Animal Care and Protection Act 2001.

\subsection{Experiment 1: Concentration and Number of Injection Sites}

To test whether different concentrations and number of injection sites influenced the effectiveness in killing COTS, we conducted a factorial experiment. We tested three different concentrations of citric acid in seawater solution $\left(90,120\right.$, and $150 \mathrm{~g} \cdot \mathrm{L}^{-1}$ ) crossed with three different numbers of injection sites (one, two, and four injection sites, hereafter I.S.). Six replicate COTS were injected in each of the 
nine treatment combinations (three citric acid concentrations $\times$ three injection site levels) using a total of 54 individual COTS. In addition, five COTS per I.S. treatment level were injected with $20 \mathrm{~mL}$ of seawater to control for the injection itself. All treatments were run simultaneously, except the three $90 \mathrm{~g} \cdot \mathrm{L}^{-1}$ treatments and the 4 I.S., $120 \mathrm{~g} \cdot \mathrm{L}^{-1}$ treatments, where COTS were injected in bunches of three (each still in individual tanks). The second bunch was injected $\sim 24 \mathrm{~h}$ after the first one to keep the start of the experiment at a similar time of day, therefore minimizing any variation in water temperature.

A 16-gauge stainless steel needle mounted on a $25 \mathrm{~mL}$ disposable syringe was chosen to perform the injection in order to minimise puncture size and leakage postinjection [12]. Injections were performed at the base of the arms [10], targeting the hydrovascular system of the starfish [19]. Single injections were administered at a randomly selected arm, double injections at opposing arms, and four injections in different quartiles. For each treatment, a total of $20 \mathrm{~mL}$ of solution was evenly split between injection sites (one I.S. treatment $=20 \mathrm{~mL}$ injected in one arm, two I.S. treatments $=10 \mathrm{~mL}$ per arm, and four I.S. treatments $=5 \mathrm{~mL}$ per arm).

The temporal progression of the treatments was recorded every $4 \mathrm{~h}$ (three observations per day) for up to one week or until death. The clinical signs recorded were: (1) no response vs hyperactivity, (2) matting of spines, (3) swelling and loss of turgor, (4) appearance and increased production of mucus, (5) appearance of bacterial films, (6) loss of any arms or splitting, (7) immobility, and (8) death [cf. 9]. The primary response variables measured were mortality, time to immobility, and time to death, also recorded every $4 \mathrm{~h}$ (three observations per day). Immobility was defined as the inability to cling to the walls of the tank or move [12], while death was determined when all tube feet completely stopped moving $[10,20,21]$. Time to immobility was recorded because it represents the ecological death of the starfish, due to their inability to feed when immobile. In some cases, time to death was delayed by up to $38 \mathrm{~h}$ past the time of immobility as individual tube feet remained motile.

\subsection{Experiment 2: Volume}

A second experiment was performed to evaluate whether increasing the injected volume could improve the efficacy of the single injection method in achieving $100 \%$ mortality. Here, six COTS were injected with $30 \mathrm{~mL}$ of $120 \mathrm{~g} \cdot \mathrm{L}^{-1}$ solution via two simultaneous injections at the base of one arm. Injections of $15 \mathrm{~mL}$ of solution from two syringes were performed simultaneously, with the needles held approximately $5 \mathrm{~mm}$ apart (considered one I.S.). Two needles were needed to accommodate the increased volume, as larger syringes were not readily available. A maximum of $30 \mathrm{~mL}$ was used, as it is the capacity of the most commonly used gun used in the field to inject sodium bisulphate and bile salts [10]. The effect of $30 \mathrm{~mL}$ injections on mortality, time to immobility, and time to death was compared to the effect of $20 \mathrm{~mL}$ injections of $120 \mathrm{~g} \cdot \mathrm{L}^{-1}$ at one I.S. (performed in Experiment 1).

\subsection{Experiment 3: Seawater vs Distilled Water}

To compare the effect of the solvent on citric acid efficacy, we compared COTS mortality and response times when using seawater as the solvent versus distilled water. Distilled water was used to test whether a hypoosmotic reaction induced by low salinity and lower $\mathrm{pH}$ of the solvent would have increased the efficacy of the citric acid solution, increased percentage of mortality, and/or reduced time to immobility or to death. Distilled water was expected to induce an osmotic shock in COTS tissues, thereby increasing the efficiency of the citric acid injections, in two ways. First, by accentuating acidosis, because distilled water ( $\mathrm{pH}$ 7.0) is less alkaline than seawater ( $\mathrm{pH}$ 7.5-8.4) and should lower COTS coelomic $\mathrm{pH}$ after citric acid injection. Second, by causing a hypoosmotic shock, because COTS are unable to tolerate drastic changes in internal salinity or osmotic pressure [13,16]. Distilled water was used as the solvent in one treatment (one I.S., $20 \mathrm{~mL}$ of $120 \mathrm{~g} \cdot \mathrm{L}^{-1}$ citric acid solution) repeated on six individuals. The effect of distilled water on mortality, time to immobility, and time to death was compared to the effect of $20 \mathrm{~mL}$ injections of $120 \mathrm{~g} \cdot \mathrm{L}^{-1}$ at one I.S. (performed in Experiment 1). 


\subsection{Statistical Analysis}

For Experiment 1, differences between times to immobility and to death were analysed using two-way fixed factor analysis of covariance (ANCOVAs). Because only treatments that reached $100 \%$ mortality were included in these models, none of the single injection site treatments were included in the statistical tests for Experiment 1. Additionally, for the $150 \mathrm{~g} \cdot \mathrm{L}^{-1}, 4 \mathrm{I} . \mathrm{S} ., 20 \mathrm{~mL}$ seawater treatment, specific hours of immobility and death were not attained because all COTS reached immobility and died overnight. Therefore, death was assumed to have occurred at the same time as immobility, and both times were scored at the following morning observation. For all analyses, assumptions of normality among residuals were analysed using the Shapiro-Wilk test (time to immobility: $\mathrm{W}=0.787$, $p<0.001$; time to death: $\mathrm{W}=0.772, p<0.001$ ). Homogeneities of variances between concentrations and number of injection sites were analysed with Levene's test. Time to immobility and to death measurements were subsequently log transformed to meet assumptions of normality: $\log$ (time to immobility): $\mathrm{W}=0.958, p=0.317 ; \log$ (time to death): $\mathrm{W}=0.950, p=0.118$. The dependent variables were time to immobility and to death (hours), analysed separately, and the independent fixed factors were the concentrations of the solution (three levels: 90,120,150 g. $\mathrm{L}^{-1}$ ) and the number of injection sites (two levels: two and four I.S.). To control for the effect of body size, we used the diameter of the starfish as covariate. Because the interaction terms among size, concentration, and number of injection sites were not significant for time to immobility and to death, the full models were rerun without the interaction terms to increase the power of the tests. Tukey's post hoc tests were used to analyse statistical differences between concentration groups and I.S. treatments.

For Experiments 2 and 3, differences between times to immobility and to death (dependent variables) were analysed separately using one-way ANCOVAs with volume and water type as independent fixed parameters, while using the diameter of the starfish as covariate. Assumptions of normality were analysed with the Shapiro-Wilk test of normality (Experiment 2, time to immobility: $\mathrm{W}=0.978, p=0.954$, time to death: $\mathrm{W}=0.901, p=0.226$; Experiment 3, time to immobility: $\mathrm{W}=0.876$, $p=0.144$, time to death: $\mathrm{W}=0.878, p=0.152$ ) and homogeneity of variances were analysed with Levene's tests. No transformations were required. Because the interaction terms between size and volume and size and water type were not significant for time to immobility and to death, the full models were rerun without the interaction terms to increase the power of the tests. Statistical analyses were conducted using TIBCO Spotfire S+ ${ }^{\circledR} 8.2$ Programmer's Guide, TIBCO Software Inc. (Palo Alto, CA, United States) Technical Support.

\section{Results}

\subsection{Experiment 1: Concentration and Number of Injection Sites}

All treatments using either two or four injection sites had 100\% mortality, regardless of the citric acid concentration (Figure 1) or of COTS size (Table 1). Concentration significantly affected time to immobility (Table 1), with the $120 \mathrm{~g} \cdot \mathrm{L}^{-1}$ treatments being almost twice as fast $(32.2 \pm 8.2 \mathrm{~h}$ SEM) than the $90 \mathrm{~g} \cdot \mathrm{L}^{-1}$ treatments $(69.9 \pm 18.7 \mathrm{~h})$. In contrast, the concentration of citric acid did not have a significant impact on time to death (Table 1), although the $150 \mathrm{~g} \cdot \mathrm{L}^{-1}$ treatments were, on average, 1.8 times faster than the $90 \mathrm{~g} \cdot \mathrm{L}^{-1}$ ones (respectively, $46.8 \pm 7.4 \mathrm{~h}$ and $84.4 \pm 18.7 \mathrm{~h}$ ). Time to death was instead significantly affected by the number of injection sites (Table 1), as COTS with more injections died faster. On average, four injections halved the time to death compared to two injections $(44.1 \pm 6.7 \mathrm{~h}$ and $79.2 \pm 12.1 \mathrm{~h}$, respectively). In contrast, time to immobility was not affected by number of injection sites (Table 1), although four injections immobilised COTS twice as fast as two injections (respectively, $32.8 \pm 6.2 \mathrm{~h}$ and $59.6 \pm 12.8 \mathrm{~h}$ ). The $150 \mathrm{~g} \cdot \mathrm{L}^{-1}$, four I.S. treatment was the quickest overall at killing COTS $(26.4 \pm 4 \mathrm{~h})$, and was 4.3 times faster than the $90 \mathrm{~g} \cdot \mathrm{L}^{-1}$, double injection. The latter was the slowest treatment that still achieved $100 \%$ mortality and took $112.8 \pm 31.8 \mathrm{~h}$ (Figure 1). 


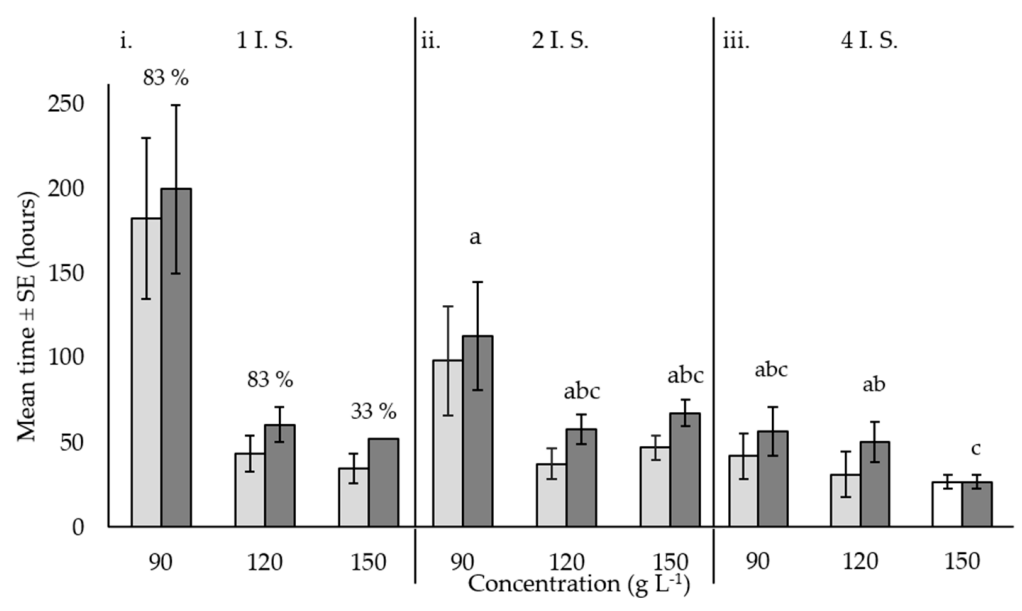

Figure 1. The effects of citric acid concentration and the number of injections. Mean time to immobility (口) and to death (口) \pm standard error for Acanthaster cf. solaris injected with $20 \mathrm{~mL}$ of citric acid and seawater solution at concentrations of 90,120 , and $150 \mathrm{~g} \cdot \mathrm{L}^{-1}$ in one (i), two (ii) and four (iii) injection sites (I.S.). Numbers above bars represent total percent mortality; where no numbers are shown, mortality was equal to $100 \%$. For the $150 \mathrm{~g} \cdot \mathrm{L}^{-1}, 4$ I.S. treatment, time to immobility was assumed to equal time to death ( $\square$ ). Six replicates per treatment combination were used. Letter notations above bars $(a, b, c)$ indicate Tukey's post-hoc groupings between injection site treatments and concentrations for time to death. Different letters indicate significant differences among treatments.

When a single injection was administered, mortality depended on the concentration used. At 90 and $120 \mathrm{~g} \cdot \mathrm{L}^{-1}$, mortality was $83 \%$ (five out of six starfish died), while at $150 \mathrm{~g} \cdot \mathrm{L}^{-1}$ mortality decreased to $33 \%$ (only two out of six starfish died, Figure 1). However, increasing the concentration reduced time to immobility by 5 -fold and time to death 4 -fold. At $90 \mathrm{~g} \cdot \mathrm{L}^{-1}$, COTS were immobile in $182.8 \pm 47.1 \mathrm{~h}$ and died in $200 \pm 50 \mathrm{~h}$, while at $150 \mathrm{~g} \cdot \mathrm{L}^{-1}$ they were immobile in $35 \pm 8.5 \mathrm{~h}$ and died in $\sim 50 \mathrm{~h}$.

Behaviour and Macroscopic Progression

Immediately after injection with citric acid, COTS showed symptoms of stress through hyperactivity, swelling, and increased mucus production. Approximately one day after injection, mucus production, matting of the spines, and localised necrosis on at least one arm were common symptoms. Additionally, many specimens, particularly those treated with higher concentrations, were already partly immobile or dead and others had split in half or thirds. In some cases, tissue decomposition progressed over the central disc, exposing internal organs. After two days, the first dense colonies of bacteria started forming, creating orange-red films around decomposing parts of COTS. Matting of the spines was usually body-wide, and some spines had been dropped or were bleached. Starfish motility was usually very low, with most animals completely immobile or dead. Three to four days after injection, tissue necrosis and bacterial decomposition progressed. By this time, most COTS were considered unrecoverable, completely immobile, or dead. However, in some cases where the starfish had split, one half was completely dead and decomposing while the other half, or a few roaming arms, remained alive for up to $10 \mathrm{~d}$ postinjection, before eventually dying. These individuals (eight) were scored as survivors in our analyses, because they were still alive during the observation period.

\subsection{Experiment 2: Volume}

Increasing the volume of citric acid solution from 20 to $30 \mathrm{~mL}$ did not increase the percentage of mortality in the starfish injected once with the $120 \mathrm{~g} \cdot \mathrm{L}^{-1}$ solution, which remained at $83 \%$ (five out of six COTS died in both treatments) (Figure 2). However, increasing the volume accelerated the mean 
time to immobility by around $\sim 20 \%$, from $43.8 \pm 10.3 \mathrm{~h}(20 \mathrm{~mL})$ to $37.2 \pm 10.1 \mathrm{~h}(30 \mathrm{~mL})$, although this difference was not statistically significant (Table 1). Time to death was also not significantly affected by changes in the injected volume (Table 1), although higher volumes resulted in a $27 \%$ decrease in time to death, passing from $60.7 \pm 10.3 \mathrm{~h}(20 \mathrm{~mL})$ to $47.8 \pm 9.3 \mathrm{~h}(30 \mathrm{~mL})$ (Figure 2).

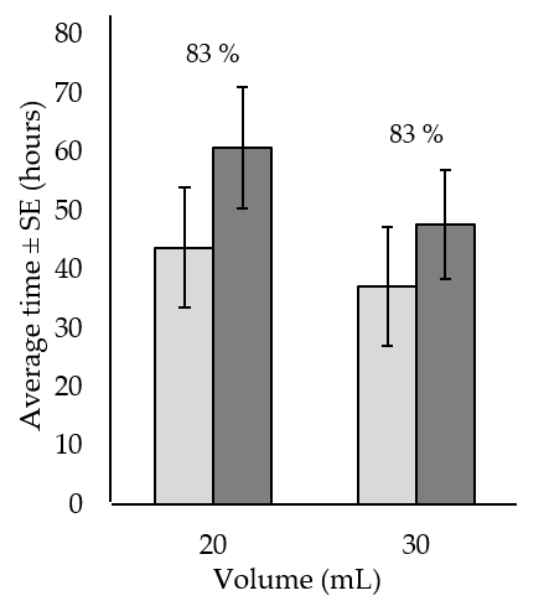

Figure 2. The effect of volume on response to citric acid injections. Mean time to immobility ( $\square$ ) and to death $(\square) \pm$ standard error for Acanthaster cf. solaris injected in one site with either $20 \mathrm{~mL}$ or $30 \mathrm{~mL}$ of $120 \mathrm{~g} \cdot \mathrm{L}^{-1}$ citric acid and seawater solution. Numbers above bars represent total percent mortality for each treatment. Six replicates per treatment were used.

\subsection{Experiment 3: Water Type}

Seawater appeared to be a better solvent than distilled water, as it resulted in (1) higher mortality and (2) $\sim 30 \%$ reduction in time to immobility and to death, although these differences were not significant (Figure 3, Table 1). Seawater killed five out of six COTS (or 83\%), while distilled water only killed four out of six COTS (or 67\%). Additionally, the seawater treatment caused immobility in $43.8 \pm 10.3 \mathrm{~h}$, while the distilled water solvent took $59.4 \pm 22.5 \mathrm{~h}$ (Figure 3). Similarly, COTS injected with seawater solution died in $60.7 \pm 10.3 \mathrm{~h}$, while those injected with the distilled water solution died in $77.8 \pm 22.6 \mathrm{~h}$.

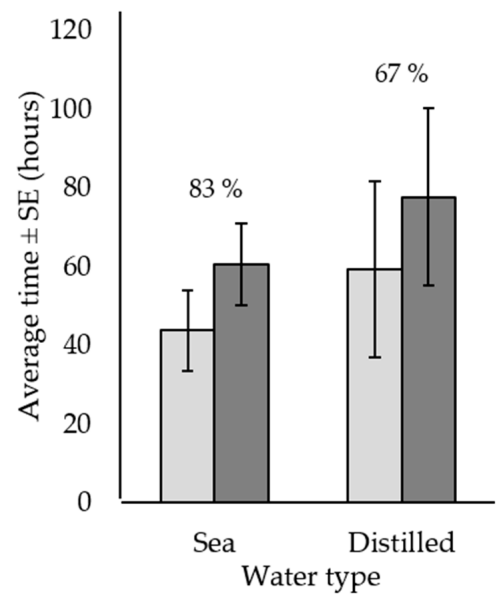

Figure 3. The effect of solvent on responses to citric acid injections. Mean time to immobility ( $\square$ ) and to death (口) \pm standard error for Acanthaster cf. solaris injected in one site with $20 \mathrm{~mL}$ of $120 \mathrm{~g} \cdot \mathrm{L}^{-1}$ citric acid and either seawater or distilled water solution. Numbers above bars represent total percent mortality for each treatment. Six replicates per treatment were used. 
Table 1. Results of the analysis of covariance (ANCOVA) on time to immobility and to death for Acanthaster cf. solaris injected with citric acid. Experiment 1 tests the response to acid concentration $\left(90,120\right.$, or $\left.150 \mathrm{~g} \cdot \mathrm{L}^{-1}\right)$ and number of injection sites (two or four). Experiment 2 tests the effect of injection volume $(20 \mathrm{~mL}$ or $30 \mathrm{~mL})$. Experiment 3 tests the effect of distilled water or seawater as solvent for the citric acid. Body diameter was used as covariate in all models. Data for Experiment 1 were $\log$ transformed. * indicates significance at $\mathrm{P}<0.05$.

\begin{tabular}{|c|c|c|c|c|c|}
\hline Source & DF & SS & MS & $\mathbf{F}$ & $\mathbf{P}$ \\
\hline \multicolumn{6}{|c|}{ Experiment 1: two-way ANCOVA } \\
\hline Size & 1 & 0.20 & 0.20 & 0.18 & 0.677 \\
\hline Concentration & 2 & 8.94 & 4.47 & 3.91 & 0.031 * \\
\hline Injection sites & 1 & 1.74 & 1.74 & 1.53 & 0.226 \\
\hline Error & 30 & 34.23 & 1.14 & & \\
\hline \multicolumn{6}{|c|}{ Log(Time to Death) } \\
\hline Size & 1 & 0.01 & 0.01 & 0.02 & 0.882 \\
\hline Concentration & 2 & 1.35 & 0.68 & 2.49 & 0.100 \\
\hline Injection sites & 1 & 2.82 & 2.82 & 10.37 & 0.003 * \\
\hline Error & 30 & 8.16 & 0.27 & & \\
\hline \multicolumn{6}{|c|}{ Experiment 2: one-way ANCOVA } \\
\hline Size & 1 & 196.60 & 196.60 & 0.34 & 0.579 \\
\hline Volume & 1 & 23.44 & 23.44 & 0.04 & 0.847 \\
\hline Error & 7 & 4070.46 & 581.49 & & \\
\hline \multicolumn{6}{|l|}{ Time to Death } \\
\hline Size & 1 & 709.08 & 709.08 & 1.43 & 0.270 \\
\hline Volume & 1 & 96.74 & 96.74 & 0.20 & 0.671 \\
\hline Error & 7 & 3454.80 & 493.54 & & \\
\hline \multicolumn{6}{|c|}{ Experiment 3: one-way ANCOVA } \\
\hline Size & 1 & 61.44 & 61.44 & 0.05 & 0.836 \\
\hline Water type & 1 & 800.55 & 800.55 & 0.61 & 0.465 \\
\hline Error & 6 & 7878.63 & 1313.11 & & \\
\hline \multicolumn{6}{|l|}{ Time to Death } \\
\hline Size & 1 & 367.11 & 367.11 & 0.30 & 0.603 \\
\hline Water type & 1 & 1241.10 & 1241.10 & 1.01 & 0.352 \\
\hline Error & 6 & 7333.14 & 1222.19 & & \\
\hline
\end{tabular}

\section{Discussion}

This study demonstrated that injections of citric acid powder and seawater solution represent an efficient, economical, and easy-to-use method to cull crown-of-thorns starfish (COTS). We found that injecting $20 \mathrm{~mL}$ of seawater and citric acid powder at a concentration of $90-150 \mathrm{~g} \cdot \mathrm{L}^{-1}$ in two or four opposing arms effectively kills $100 \%$ of COTS, with times to death comparable to that of bile salts, vinegar, and lime juice (Table 2). Although time to death was higher for the two injections method ( $\sim 58 \mathrm{~h},\left[120 \mathrm{~g} \cdot \mathrm{L}^{-1}\right.$ citric acid) compared to four ( 26 h, [150 g. $\mathrm{L}^{-1}$ citric acid]), we argue that the reduced handling time makes the two injections method the most cost and time effective for operations in the field.

Mortality rates were significantly affected by both the number of injections and the concentration used. Indeed, for the single injection treatments, increasing the concentration from $90-120 \mathrm{~g} \cdot \mathrm{L}^{-1}$ to $150 \mathrm{~g} \cdot \mathrm{L}^{-1}$ reduced mortality from $83 \%$ to $33 \%$. This concentration-related decrease in mortality may have occurred because the high localised dose of acid induced rapid, local necrosis of the injected area, with consequent loss of one or more arms, while the rest of the body survived. In contrast, all the multiple injection treatments reached $100 \%$ mortality, regardless of the concentration used, perhaps 
because the acidic solution was more evenly spread throughout the starfishes' bodies. While the precision of mortality rates within each of our treatments is quite low (with six replicates, the error is $1 / 6$ or $16.6 \%$ ) multiple injections were conclusively effective at culling all COTS thus treated. All 36 specimens treated with multiple injections died (18 double and 18 quadruple injections, with a combined sampling error for multiple injections of 5.5\%).

For the treatments that reached $100 \%$ mortality (double and quadruple injections), time to immobility significantly decreased with increasing concentration, dropping from $70 \pm 19 \mathrm{~h}$ for the $90 \mathrm{~g} \cdot \mathrm{L}^{-1}$ to $37 \pm 5 \mathrm{~h}$ for the $150 \mathrm{~g} \cdot \mathrm{L}^{-1}$ solution. Contrarily, time to death was not affected by concentration, but by the number of injections: four injections halved the time to death compared to two (respectively, $44 \pm 7 \mathrm{~h}$ and $79 \pm 12 \mathrm{~h}$ ). However, due to the low number of replications for each treatment in this study, specific times to immobility and to death should only be used as guidelines for which is the most effective (fastest) method, and not as accurate indicators of true times to immobility and to death.

Another determinant factor affecting times to immobility and to death in this study was the incredible resistance of some roaming arms, which in some cases survived for up to 10 days postinjection. However, although COTS can regenerate from extensive tissue loss [22,23], it is unlikely that these roaming parts would have caused further coral loss, because of the absence of central disc and pyloric caeca, and the increased predation caused by chemoattraction of predators to injured COTS [24,25]. Therefore, we consider the lag time in reaching death, found herein, to be inconsequential.

Because none of the single injection treatments of Experiment 1 reached 100\% mortality, we evaluated whether using distilled water as solvent or increasing the injected volume could improve the efficiency of citric acid single injections. Distilled water was expected to induce an osmotic shock in COTS tissues, thus increasing the efficiency of the citric acid injections. On the contrary, it reduced mortality and slowed time to immobility and to death. This may have happened because the hypoosmotic conditions caused by distilled water activated the opening of the water vascular system in attempt to restore the physiological osmolarity [26], leading to the exchange of water with the environment and consequently flushing out the citric acid. In contrast, COTS injected with seawater may not have had the possibility of doing so, lacking the hypoosmotic triggering factor. Therefore, we argue that distilled water should not be used as a solvent for the citric acid injections. Similarly, increasing the volume of a single injection of citric acid from 20 to $30 \mathrm{~mL}$ did not increase the percent mortality, although it moderately reduced time to immobility and to death. Likewise, a single injection of 10,15 , and $20 \mathrm{~mL}$ of lime juice failed to achieve $100 \%$ mortality and is therefore not an effective method to cull COTS [15]. We conclude that single injections of citric acid should not be performed on COTS in the field, given that mortality with single injection methods only reached $83 \%$.

COTS death by citric acid injections is most likely induced by chronic $\mathrm{pH}$ stress caused by the low $\mathrm{pH}$ of the solution injected, which ranged between $\sim 1.6$ and 1.7. Similar mechanisms of death were proposed for vinegar ( $\mathrm{pH} 2.2)$ and lime juice $(\mathrm{pH} 1.8)$ [12,15]. Indeed, echinoderms are poor acid-base regulators [27], and citric acid, like acetic acid, is both water-soluble and lipid-soluble, so it can easily perfuse into COTS tissues, where the low tissue $\mathrm{pH}$ causes protein degeneration and tissue necrosis $[12,17]$.

This study showed that injection with citric acid is an efficient way of culling COTS, and thus of potentially controlling localised outbreaks. But why should this method be used over other current alternatives like sodium bisulphate, bile and cooking salts, vinegar, or lime juice? Compared to the single injection of bile salts [10] and vinegar [12], this method may be slightly more time consuming, because, from the data available, at least two injections per starfish are required to achieve $100 \%$ mortality. Nevertheless, citric acid has several characteristics that make it a valid alternative to those control methods (Table 2). First, compared to both sodium bisulphate and bile salts, it is generally available for purchase from a variety of stores. Indeed, rapid intervention, which is crucial to the successful control initiatives against COTS outbreaks $[1,28,29]$, is possible only with a reliable and easy access to the chemical product. However, due to quarantine restrictions and high importation 
cost, bile salts may be inaccessible for some remote island communities that experience recurrent COTS outbreaks throughout the Indo-Pacific. Secondly, citric acid has a favourable ecological profile (compared, for example, to sodium bisulphate) and is unlikely to accumulate in soil or sediment, as it is rapidly degraded by naturally occurring bacteria [30-32]. Additionally, predators feeding upon decomposing COTS would not be expected to suffer from ingestion of acidic tissues. Investigations on the environmental side effects of similar natural acidic products (lime juice and vinegar) have found no evidence of an impact on other marine organisms [12,15,17]. Third, in contrast to vinegar and lime juice, citric acid is easily transportable as a lightweight powder which can be mixed on site with seawater, reducing transportation costs and volumes on land. It also has a long shelf life, allowing storage in remote areas where fresh citrus juice may not be available or rapidly deteriorate. Additionally, compared to extracting juice from fresh limes, using powdered citric acid is far less labour intensive and more readily available (limes are seasonal and their price can vary greatly).

Until effective measures to prevent COTS outbreaks are found, having a collective workforce and/or volunteers "adopt a reef" may be the most efficient way of deploying COTS treatments and thereby preventing further mass coral predation. However, some important considerations need to be made. Firstly, permits need to be obtained from relevant local authorities. Secondly, safety guidelines for operators are needed to avoid spiking hazards from COTS spines and syringe needles, and for correct handling of citric acid powder to avoid skin, eye, and respiratory inflammations. Thirdly, further studies should aim at developing a single injection protocol for citric acid and investigate the efficiencies of injecting citric acid in different parts of COTS bodies (i.e., distal and medial portion of the arm and central disc). Finally, considering that the objective of COTS control programmes is prevention of extensive coral mortality and not the eradication of the species, injections should be carried out only if more than four to five COTS are counted during a $15 \mathrm{~min}$ swim, considered active outbreaking density [11]. If an outbreak is identified, citric acid solution $\left[\sim 90-150 \mathrm{~g} \cdot \mathrm{L}^{-1}\right]$ can be easily prepared by mixing the solid powder with seawater; $20 \mathrm{~mL}$ of solution can then be administered with double or quadruple injections using any syringe attached to a veterinary $16 \mathrm{Ga} \times 1 / 2$ " needle, both easily available from any chemist store. It is important to note, however, that we caution against the use of citric acid until large-scale field trials have been undertaken. Citric acid is a promising alternative to existing COTS control techniques due to the ease of access, transport, storage, handling, and delivery compared to current methods. As such, it provides a new option to combat COTS outbreaks that is especially useful in remote locations and developing countries. 
Table 2. Comparison of the chemicals currently available for injections of Acanthaster cf. solaris (crown-of-thorns starfish (COTS)).

\begin{tabular}{|c|c|c|c|c|}
\hline & Absolute Lethal Dose $\left(\mathrm{LD}_{100}\right)$ & Time to Death & Advantages & Disadvantages \\
\hline Sodium bisulphate & $\begin{array}{l}\text { Multiple injections of up to } 180 \mathrm{~mL}[33] \\
\text { of } 140 \mathrm{~g} \cdot \mathrm{L}^{-1} \text { solution }[8,9]\end{array}$ & Unreported & -Highly effective & $\begin{array}{l}\text {-Multiple injections required } \\
\text {-Potent oxygen scavenger }[8,9]\end{array}$ \\
\hline Bile salts & $\begin{array}{l}1 \times 10 \mathrm{~mL} \text { injection } \\
\text { of } 8 \mathrm{~g} \cdot \mathrm{L}^{-1} \text { solution }[10]\end{array}$ & $\sim 28 \mathrm{~h}[10]$ & $\begin{array}{l}\quad \text {-Single injection } \\
\text {-No known environmental side effects }\end{array}$ & $\begin{array}{l}\text {-Not readily available in remote areas } \\
\text {-Quarantine restrictions on access } \\
-<0.05 \text { to } 0.29 \text { USD per injection }[10,15,18,33]\end{array}$ \\
\hline Cooking salt & $\begin{array}{c}2 \times 10 \mathrm{~mL} \text { injections } \\
\text { of } 400 \mathrm{~g} \cdot \mathrm{L}^{-1} \text { solution }[13,16]\end{array}$ & $\sim 48 \mathrm{~h} \mathrm{[16]}$ & $\begin{array}{c}\text {-Readily available } \\
\text {-No known environmental side effects } \\
-<0.05 \text { USD per COTS [13] }\end{array}$ & $\begin{array}{l}\text {-High quantities required }(8 \mathrm{~kg} / 1000 \mathrm{COTS}) \\
\text {-Solution preparation requires heating } \\
\text {-Precipitation and crystallization [16] }\end{array}$ \\
\hline Vinegar & $\begin{array}{c}2 \times 10 \mathrm{~mL} \text { injections [12,18] or } \\
1 \times 25 \text { mL injection [15] }\end{array}$ & $\sim 30 \mathrm{~h}[15], \sim 40 \mathrm{~h}[12]$ & $\begin{array}{c}\text {-Single injection } \\
\text {-Readily available } \\
\text {-No known environmental side effects } \\
-<0.05 \text { USD per COTS [15] }\end{array}$ & -High quantities required (20-25 L/1000 COTS) \\
\hline Lime juice & $2 \times 10 \mathrm{~mL}$ injections $[15,18]$ & $\sim 20 \mathrm{~h} \mathrm{[15]}$ & -No known environmental side effects [15] & $\begin{array}{l}\text {-High quantities required (20 L/1000 COTS) } \\
\text {-Laborious process for juice extraction } \\
\text {-Seasonal and not ubiquitously cheap } \\
\text {-Perishable }\end{array}$ \\
\hline Powdered Citric acid ${ }^{\text {a }}$ & $\begin{array}{l}2 \times 10 \mathrm{~mL} \text { or } 4 \times 5 \mathrm{~mL} \text { injections } \\
\text { of } 90-150 \mathrm{~g} \cdot \mathrm{L}^{-1} \text { solution }\end{array}$ & $\sim 26 \mathrm{~h}^{\mathrm{b}}$ & $\begin{array}{c}\text {-Readily available, long shelf life } \\
\text {-No known environmental side effects } \\
\quad-<0.05 \text { USD per COTS a } \\
\text {-Easily transportable (180-300 g/1000 COTS) }\end{array}$ & Multiple injections required \\
\hline
\end{tabular}

a This study. ${ }^{\mathrm{b}}$ Four injections of $150 \mathrm{~g} \cdot \mathrm{L}^{-1}$ solution of citric acid. 
Acknowledgments: This study was funded by a grant to Lisa Boström-Einarsson from the Ian Potter Foundation 50th Anniversary COTS Control Grant to the Australian Museum's Lizard Island Research Station (LIRS), and by James Cook University. We wish to thank Robert Streit for helping in the field and laboratory work, Anne Hoggett and Lyle Vail for their assistance at the Lizard Island Research Station and Rie Hagiara for the statistical help.

Author Contributions: A.B., L.B.E. and N.G. conceived and designed the experiments; A.B and L.B.E. performed the experiments; A.B analysed the data; A.B. wrote the majority of the paper; L.B.E. and N.G. edited the manuscript.

Conflicts of Interest: The authors declare no conflict of interest. The founding sponsors had no role in the design of the study; in the collection, analyses, or interpretation of data; in the writing of the manuscript, and in the decision to publish the results

\section{References}

1. Birkeland, C.; Lucas, J. Acanthaster planci: Major Management Problem of Coral Reefs; CRC press: Boca Raton, FL, USA, 1990.

2. Pratchett, M.S.; Caballes, C.F.; Rivera-Posada, J.A.; Sweatman, H.P.A. Limits to understanding and managing outbreaks of crown-of-thorns starfish (Acanthaster spp.). Oceanogr. Mar. Biol. Ann. Rev. 2014, 52, 133-200.

3. Chesher, R.H. Destruction of Pacific corals by the sea star Acanthaster planci. Science 1969, 165, $280-283$. [CrossRef] [PubMed]

4. Osborne, K.; Dolman, A.M.; Burgess, S.C.; Johns, K.A. Disturbance and the dynamics of coral cover on the Great Barrier Reef (1995-2009). PLoS ONE 2011, 6, e17516. [CrossRef] [PubMed]

5. De'ath, G.; Fabricius, K.E.; Sweatman, H.; Puotinen, M. The 27-year decline of coral cover on the Great Barrier Reef and its causes. Proc. Nat. Acad. Sci. 2012, 109, 17995-17999. [CrossRef] [PubMed]

6. Rivera-Posada, J.; Owens, L.; Caballes, C.F.; Pratchett, M.S. The role of protein extracts in the induction of disease in Acanthaster planci. J. Exp. Mar. Biol. Ecol. 2012, 429, 1-6. [CrossRef]

7. Hughes, T.P.; Graham, N.A.; Jackson, J.B.; Mumby, P.J.; Steneck, R.S. Rising to the challenge of sustaining coral reef resilience. Trends Ecol. Evol. 2010, 25, 633-642. [CrossRef] [PubMed]

8. Rivera-Posada, J.; Pratchett, M.S. A review of existing control efforts for Acanthaster planci; limitations to successes. Report to the Department of Sustainability, Environment, Water, Population \& Communities, NERP, Tropical Environmental Hub: Townsville, Australia, 2012. Available online: http:/ / citeseerx.ist.psu. edu/viewdoc/download?doi=10.1.1.721.3890\&rep=rep1\&type=pdf (accessed on 20 April 2015).

9. Rivera-Posada, J.; Caballes, C.F.; Pratchett, M.S. Lethal doses of oxbile, peptones and thiosulfate-citratebile-sucrose agar (TCBS) for Acanthaster planci; exploring alternative population control options. Mar. Poll. Bull. 2013, 75, 133-139. [CrossRef] [PubMed]

10. Rivera-Posada, J.; Pratchett, M.S.; Aguilar, C.; Grand, A.; Caballes, C.F. Bile salts and the single-shot lethal injection method for killing crown-of-thorns sea stars (Acanthaster planci). Ocean Coast. Manag. 2014, 102, 383-390. [CrossRef]

11. Crown-of-thorns starfish control guidelines. Great Barrier Reef Marine Park Authority: Townsville, Australia, 2014. Available online: http://hdl.handle.net/11017/2874 (accessed on 20 April 2015).

12. Boström-Einarsson, L.; Rivera-Posada, J. Controlling outbreaks of the coral-eating crown-of-thorns starfish using a single injection of common household vinegar. Coral Reefs 2016, 35, 223-228. [CrossRef]

13. De Dios, H.Y.; Sotto, B.F.; Dy, D.T.; Ilano, A.S. Response of Acanthaster planci (Echinodermata: Asteroidea) to hypersaline solution: Its potential application to population control. Galaxea 2015, 17, 23-30. [CrossRef]

14. Introduction to the Control of COTS by Acetic Acid Injection. Kuroshio Biological Research Foundation: Kochi, Japan, 2012. Available online: https://chushikoku.env.go.jp/to_2012/data/0530aa_2.pdf (accessed on 23 June 2015).

15. Moutardier, G.; Gereva, S.; Mills, S.C.; Adjeroud, M.; Beldade, R.; Ham, J.; Kaku, R.; Dumas, P. Lime Juice and Vinegar Injections as a Cheap and Natural Alternative to Control COTS Outbreaks. PLoS ONE 2015, 10, e0137605. [CrossRef] [PubMed]

16. Rivera-Posada, J.; Owens, L. Osmotic shock as alternative method to control Acanthaster planci. J. Coastal Life Med. 2014, 2, 99-106. [CrossRef]

17. Yamamoto, T.; Otsuka, T. Experimental validation of dilute acetic acid solution injection (Acanthaster planci). Naturalistae 2013, 17, 63-65. 
18. Dumas, P.; Gereva, S.; Moutardier, M.; Ham, J.; Kaku, R. Collective action and lime juice fight crown-of-thorns starfish outbreaks in Vanuatu. SPC Fish. Newsl. 2015, 146, 47-52. Available online: http://www.spc.int/ DigitalLibrary/Doc/FAME/InfoBull/FishNews/146/FishNews146_47_Dumas.pdf (accessed on 23 June 2015).

19. Nichols, D. The water-vascular system in living and fossil echinoderms. Palaeontology 1972, 15, 519-538.

20. Rivera-Posada, J.; Pratchett, M.S.; Cano-Gómez, A.; Arango-Gómez, J.; Owens, L. Injection of Acanthaster planci with thiosulfate-citrate-bile-sucrose agar (TCBS). I. Disease induction. Dis. Aquat. Organ. 2011, 97, 85-94. [CrossRef] [PubMed]

21. Pratchett, M.S.; Rivera-Posada, J.; Aguilar, C.; Caballes, F.C.; Grand, A. Efficacy of Oxbile for Controlling Outbreak Populations of Acanthaster Planci on the Great Barrier Reef; Great Barrier Reef Marine Park Authority: Townsville, QLD, Australia, 2007; pp. 1-8.

22. Sweatman, H.; Butler, I. An experimental investigation of the ability of adult crown-of-thorns starfish to survive physical damage. In The Possible Causes and Consequences of Outbreaks of the Crown-of-Thorns Starfish, Proceedings of a Workshop series No 18, Townsville, QLD, Australia, 10 June 1992; Engelhardt, U., Lassing, B., Eds.; Great Barrier Reef Marine Park Authority: Townsville, Australia, 1993; pp. 71-82.

23. Messmer, V.; Pratchett, M.S.; Clark, T. Capacity for regeneration in crown of thorns starfish, Acanthaster planci. Coral Reefs 2013, 32, 461. [CrossRef]

24. Glynn, P.W. Acanthaster population regulation by a shrimp and a worm. In Proceedings of the Fourth International Coral Reef Symposium, Manila, Phillippines, 1981; Gomez, E.D., Birkeland, C.E., Buddemeier, R.W., Johannes, R.E., Marsh, J.A., Tsuda, R.T., Eds.; Marine Sciences Center: Quezon City, Phillippines, 1982; Volume 2, pp. 607-612.

25. Glynn, P.W. An amphinomid worm predator of the crown-of-thorns sea star and general predation on asteroids in eastern and western Pacific coral reefs. Bull. Mar. Sci 1984, 35, 54-71.

26. Santos-Gouvea, I.A.; Freire, C.A. Effects of hypo-and hypersaline seawater on the microanatomy and ultrastructure of epithelial tissues of Echinometra lucunter (Echinodermata: Echinoidea) of intertidal and subtidal populations. Zool. Stud. 2007, 46, 203-215.

27. Wittmann, A.C.; Pörtner, H.O. Sensitivities of extant animal taxa to ocean acidification. Nat. Clim. Chang. 2013, 3, 995-1001. [CrossRef]

28. Yamaguchi, M. Acanthaster planci infestations of reefs and coral assemblages in Japan: A retrospective analysis of control efforts. Coral Reefs 1986, 5, 23-30. [CrossRef]

29. Bos, A.R.; Gumanao, G.S.; Mueller, B.; Saceda-Cardoza, M.M. Management of crown-of-thorns sea star (Acanthaster planci L.) outbreaks: Removal success depends on reef topography and timing within the reproduction cycle. Ocean Coast. Manage. 2013, 71, 116-122. [CrossRef]

30. Human and Environmental Risk Assessment on ingredients of Household Cleaning Products. Substance: Citric Acid and Salts (CAS\# 77-92-9; 5949-29-1; 6132-04-3). 2005. Available online: http:/ /www.heraproject. com/files/37-f-05-hera_citricacid_version1_april05.pdf (accessed on 23 June 2015).

31. Hoyt, H.L.; Gewanter, H.L. Citrate. In Detergent; De Oude, N.T., Ed.; Springer: Berlin/Heidelberg, Germany, 1992; Volume 3, pp. 229-242. [CrossRef]

32. OECD SIDS. Citric Acid CAS N77-92-9. 2001. Available online: http://www.inchem.org/documents / sids/sids/77929.pdf (accessed on 23 June 2015).

33. Great Barrier Reef Marine Park Authority. Crown-of-thorns starfish control guidelines. GBRMPA: Townsville, Australia, 2014. Available online: http://www.gbrmpa.gov.au/_data/assets/pdf_file/0006/185298/COTScontrol-guidelines.pdf (accessed on 23 June 2015).

(C) 2016 by the authors; licensee MDPI, Basel, Switzerland. This article is an open access article distributed under the terms and conditions of the Creative Commons Attribution (CC-BY) license (http://creativecommons.org/licenses/by/4.0/). 